\title{
A "HISTÓRIA" DO ATRASO BRASILEIRO UMA RELEITURA DE CELSO FURTADO E RAYMUNDO FAORO NA ÓTICA DA NOVA ECONOMIA INSTITUCIONAL DE DOUGLASS NORTH'
}

\author{
THE "HISTORY" OF THE BRAZILIAN DE LAY \\ ARE READIN GOF CELSO FURTADO AND RAYMUNDO \\ FAORO THE PERSPECTIVE OF NEW INSTITUTIONAL \\ ECONOMIC SOF DOUGLASS NORTH
}

\author{
Clério Plein
}

Universidade Estadual do Oeste do Paraná - Francisco Beltrão - PR - Brasil

\begin{abstract}
Resumo: O objetivo do ensaio é buscar, nas obras de Celso Furtado e Raymundo Faoro, explicações para o atraso brasileiro que, atualmente, ainda pode ser percebido em função da pobreza e desigualdades sociais que afetam uma grande parcela da população. Trata-se de um ensaio teórico e o método consiste numa releitura desses intérpretes do Brasil com base num terceiro autor (Douglass North), representante do que se convencionou chamar de Nova Economia Institucional. Como principal conclusão, destaca-se que os três autores, ao analisarem os problemas que afetam o desenvolvimento de um país, possuem em comum a ênfase nas instituições, na história e no papel das elites.

Palavras-chave: Desenvolvimento. Instituições. Problemas estruturais. Estamento burocrático.

Abstract: The objective of this test is to look for works of Celso Furtado and Raymundo Faoro, explanations for the delay Brazilian who currently can still be perceived as a function of poverty and social inequalities that affect a large portion of the population. This is a theoretical test and the method is a reinterpretation of these interpreters of Brazil based on a third author (Douglass North) representative of the so-called New Institutional Economics. The main conclusion we emphasize that the three authors, to examine the problems affecting the development of a country have in common the emphasis on institutions, history and the role of elites.
\end{abstract}

\footnotetext{
1 A elaboração deste ensaio tem um débito com um grande mestre, Pedro Cezar Dutra Fonseca, cabendo as isenções de praxe.
} 
Keywords: Development. Institutions. Structure problems. Bureaucratic estament.

\section{INTRODUÇÃO}

O período pós Segunda Guerra (1945-1973), originalmente denominado por Hobsbawm (1995) de "os anos dourados da era de ouro do capitalismo" foi marcado por profundas mudanças políticas, tecnológicas, econômicas, sociais e culturais. Coincide com a fase desenvolvimentista da economia brasileira, profundamente marcada por três fases: intenso crescimento com os " 50 anos em 5" no governo JK, a "estagnação" que representou o declínio do Programa de Substituição de Importações e o "milagre" econômico do período militar. Do ponto de vista intelectual, trata-se de um momento de debate e efervescência de ideias em que diversos autores se debruçaram sobre o tema do desenvolvimento dos países subdesenvolvidos, ou como denominados na época, do Terceiro Mundo. Diversos autores brasileiros procuraram explicar o "atraso" do Brasil e apresentaram propostas de como modernizar o país, ou seja, faziam um diagnóstico e apresentavam um programa de ação. São, portanto, "intérpretes do Brasil". Esses autores iniciavam a explicação no Brasil Colônia, tentando entender as raízes do problema por meio de uma abordagem histórica. Ambos convergem no sentido de que o nosso "atraso" é uma questão histórica, não genética, climática ou geográfica como queriam muitas teorias da época. Nesses termos, Caio Prado Júnior, Celso Furtado, Florestan Fernandes, Fernando Henrique Cardoso, Gilberto Freyre, Ignácio Rangel, Raymundo Faoro e Sérgio Buarque de Holanda podem ser considerados intérpretes do Brasil.

Diante desse contexto, o objetivo deste ensaio é buscar, nos intérpretes do Brasil, uma explicação para o subdesenvolvimento do país, o que, atualmente, ainda se reflete nas desigualdades sociais, e, por conseguinte, num número expressivo de pessoas vivendo em condições de pobreza².Para dar conta da proposta, optou-se por analisar as obras de Celso Furado e Raymundo Faoro, ambos da

2Em 2000, por exemplo, os $20 \%$ mais ricos apropriavam $68,06 \%$ da renda, ao passo que os $20 \%$ mais pobres ficavam com apenas $1,5 \%$. 32,75\% da população brasileira era considerada pobre, com renda per capita média de até $R \$ 75,50$ por mês; e $16,32 \%$ indigente, com renda per capita média de até $R \$ 37,75$ por mês (PNUD, 2009). 
"geração dos anos 1950", autores de interpretações clássicas das características do desenvolvimento brasileiro.

Do ponto de vista metodológico, a releitura desses autores clássicos será feita com base na Nova Economia Institucional, sendo que nosso principal interlocutor será Douglass North, Prêmio Nobel de Economia em 1993. A opção por esta matriz de análise parte do pressuposto de que ambos os autores podem ser interpretados à luz do conceito de instituições, tão caro à Douglass North.

Assim, o ensaio está estruturado em quatro partes. Na primeira, apresenta-se uma breve síntese sobre a Nova Economia Institucional e as contribuições de Douglass North, explorando os conceitos de instituições e path dependence (dependência da trajetória histórica). Na segunda parte aborda-se algumas ideias centrais de Celso Furtado sobre os problemas estruturais no desenvolvimento econômico do Brasil. Na terceira, recorre-se à obra de Raymundo Faoro para entender a herança portuguesa através dos conceitos de patrimonialismo e estamento burocrático. Na quarta e última parte procura-se estabelecer um diálogo entre os três autores com vistas a compreender os aspectos similares nessas obras que abordam as características do desenvolvimento brasileiro.

\section{A Nova Economia Institucional de Douglass North: instituições, path dependence e desenvolvimento}

A Nova Economia Institucional (NEI) tem em Douglass North seu principal representante. Esse autor questiona os postulados clássicos da teoria neoclássica (informação completa, racionalidade dos agentes, mercados perfeitos) e sugere que a teoria neoclássica deveria incorporar as instituições para tornar seu arcabouço teórico mais realista (SIMAN, CONCEIÇÃO E FILIPPI, 2006).

De acordo com Fiani (2003, p. 136-137) a questão central do pensamento desse autor é o papel institucional do Estado. Rejeita a teoria neoclássica e "o interesse fundamental para North, ao estudar a história econômica, é explicar as suas instituições como determinantes do desempenho econômico das sociedades". "Com efeito, o problema da permanência de instituições que desfavorecem 0 crescimento econômico é uma das preocupações centrais". 
O desempenho econômico é função das instituições e de sua evolução. Juntamente com a tecnologia empregada, elas determinam os custos de transação e produção. As instituições constituem as regras do jogo numa sociedade; mais formalmente, representam os limites estabelecidos pelo homem para disciplinar as interações humanas. Consequentemente, e em compensação, estruturam incentivos de natureza política, social e econômica (NORTH, 1994b, p. 07).

Nessa abordagem, o conceito de custos de transação de Ronald Coase é central. Os custos de transação referem-se a despesas com atores que não estão diretamente envolvidos com a produção (como, por exemplo, advogados, banqueiros, contadores, funcionários de escritório, contramestres, gerentes e políticos), mas estão envolvidos com a as transações e são essenciais para a operação e coordenação do sistema econômico (NORTH, 1994b). Os custos de transação podem ser entendidos como os custos para administrar o sistema econômico.

O custo da qualificação dos atributos de valor dos bens e serviços ou do desempenho dos agentes é a chave dos custos de transação. Esse valor provém dos diversos atributos do bem ou serviço ou, no caso do desempenho do agente, das inúmeras atividades isoladas que constituem esse desempenho. (...) A segunda variável do custo do processo de troca é o tamanho do mercado que determina se o intercâmbio é pessoal ou impessoal. (...) A terceira variável é o cumprimento de obrigações assumidas. (...) Atitudes ideológicas e percepções a quarta variável - também têm peso. (...) Um mercado eficiente é consequência de instituições que, em determinado momento, oferecem avaliação e execução contratuais de baixo custo (NORTH, 1994b, p. 08-10).

O que são então, as instituições ${ }^{3}$ ? Para responder essa pergunta,

3 "Institutions are the humanly devised constrains that structure human interaction. They are made up of formal constraints (e.g., rules, laws, constitutions), informal constraints (e.g., norms of behavior, conventions, self-imposed codes of conduct), and their enforcement characteristics. Together they define the incentive structure of societies and specifically economies" (NORTH, 1994a, p. 360)."Las institucionesson imposiciones creadas por los humanos y estructuran y limitan sus interacciones. Se componen de imposiciones formales (por ejemplo, reglas, leyes, constituciones), informales (por ejemplo, normas de comportamiento, convenciones, códigos de 
Douglass North faz uma distinção entre instituições e organizações:

\begin{abstract}
as instituições compreendem regras formais, limitações informais (normas de comportamento, convenções e códigos de conduta auto-impostos) e os mecanismos responsáveis pela eficácia desses dois tipos de normas. Em suma, constituem o arcabouço imposto pelo ser humano a seu relacionamento com os outros. (...) As instituições, aliadas à tecnologia empregada, afetam os custos de transação e transformação (produção). Se as instituições constituem as regras do jogo, as organizações são os jogadores. As organizações compõem-se de grupos de indivíduos dedicados a alguma atividade executada com determinado fim. As limitações impostas pelo contexto institucional (ao lado de outras restrições normais em qualquer economia) definem o conjunto de oportunidades e, portanto, o tipo de organizações que serão criadas. Conforme a função objetiva da organização (...) buscam adquirir conhecimentos e especialização que reforcem suas possibilidades de sobrevivência em um ambiente de onipresente competição (NORTH, 1994b, p. 11-2).
\end{abstract}

No que se refere à mudança institucional, é preciso considerar que: a) os agentes da mudança são aqueles que decidem nas organizações e suas opções são determinadas por suas percepções subjetivas; b) as fontes de mudança são as oportunidades percebidas; c) o processo de mudança é gradativo; d) a direção da mudança é determinada pela dependência do curso adotado (NORTH, 1994b).

A ideia de "dependência com relação à trajetória escolhida" (NORTH, 1994b), ou seja, a path dependence (NORTH, 1994a) é um conceito central na abordagem desse autor ${ }^{4}$, que faz uma comparação entre a Inglaterra e a Espanha:

Dependência com relação à trajetória escolhida. O contraste
entre a história da Inglaterra e da Espanha e suas respectivas
colônias nos últimos 500 anos é um impressionante exemplo
da persistência de um modelo de evolução dependente da
trajetória escolhida. No caso da Inglaterra, a Magna Carta, a
evolução das garantias e direitos de propriedade e o triunfo do

conducta autoimpuestos) y sus respectivas características impositivas. En conjunto, definen la estructura de incentivos de las sociedades, y específicamente de las economias" (NORTH, 2009).

${ }^{4}$ No texto em espanhol: "dependencia de latrayectoria" (NORTH, 2009). 
Parlamento em 1689 representaram o caminho da democracia política e do crescimento econômico sustentado - modelo esse reproduzido e ampliado na América do Norte inglesa. No caso da Espanha, sua forte e centralizada burocracia administrativa um crescente volume de decretos e diretivas jurídicas que definia o curso de suas ações. Todos os detalhes da economia e da política se estruturavam com o fim de satisfazer os interesses da Coroa e criar a potência imperial mais importante desde Roma. As consequências de tudo isso foram inúmeras falências, declínio e séculos de estagnação. No Novo Mundo espanhol, o modelo de burocracia centralizada com rígido controle sobre o Estado e a economia gerou três séculos de desenvolvimento esporádico e desigual, além de instabilidade política (NORTH, 1994b, p. 23). Grifo do autor.

North (1994a; 2009), analisando o processo histórico das instituições econômicas e estruturas políticas, conclui que, enquanto a Europa Ocidental (incluindo os Países Baixos e a Inglaterra) produziram um crescimento econômico moderno, Espanha e Portugal representam exemplos de fracassos. Assim, pode-se dizer que o Brasil largou em desvantagem porque herdou de Portugal um modelo ineficiente, pois "nenhum país consegue crescer de forma consistente por um longo período de tempo sem que antes desenvolva de forma sólida suas instituições" (NORTH, 2003). Em entrevista concedida à Revista Veja, questionado sobre por que as instituições da América Latina registram um atraso histórico, North destaca que:

Nesses países, as instituições eram frágeis demais para criar uma engrenagem positiva que empurrasse a economia. México, Brasil e Argentina sempre tiveram recursos naturais suficientes para se tornar nações ricas. $O$ atraso institucional deixou esses países para trás. Há uma relação direta entre as instituições existentes nas metrópoles e o tipo de desenvolvimento que as colônias tiveram nesse campo. Quando chegaram ao Novo Mundo, os europeus carregaram sua variada cultura institucional. Os países da América Latina importaram seu modelo de Portugal e da Espanha e por isso largaram em desvantagem. A Península Ibérica colecionava instituições ineficientes, que não tinham calibre nem maturidade para estimular o crescimento econômico. Já os americanos foram fortemente influenciados pela Inglaterra e, sob a carga genética das instituições inglesas, tiveram como fonte um sistema bem mais moderno (NORTH, 2003). 
$\mathrm{Na}$ tentativa de estruturar um arcabouço institucional, ou seja, para uma aplicação desse referencial teórico, North (1994b) propõe três eixos para chegar num modelo ideal: a) as restrições institucionais (as estruturas institucionais oferecem incentivos positivos para a criação de oportunidades?); b) o processamento da informação (qual é o perfil da economia, quais são seus custos de transação e quais as instituições responsáveis por tais custos? Quais são os modelos mentais dos atores, ou seja, como encaram os problemas?); c) as organizações (empresários políticos e eleitorado).

De acordo com North (2003), "sem instituições fortes uma nação não abandona o atraso nem a pobreza". Analisando as instituições brasileiras, destaca que:

o calcanhar-de-aquiles brasileiro é a colossal desigualdade de renda que existe no país e o baixíssimo nível educacional de sua população. Essa é a ponta do iceberg. Se um país quer estrelar entre as democracias modernas e eficientes, precisa ter boa distribuição de renda e ser mais bem-educado. O fato de o Brasil ser até hoje tão desigual e deseducado é sinal de que as suas instituições ainda não estão levando o país adiante como deveria estar fazendo.

Portanto, a Nova Economia Institucional traz vários elementos para compreender a história do atraso brasileiro, e seus conceitos podem ser interessantes para reler os dois intérpretes do Brasil que serão apresentados na sequência. Primeiro, Celso Furtado e depois, Raymundo Faoro.

\section{Celso Furtado e os problemas estruturais do desenvolvimento brasileiro}

Nesta breve síntese da contribuição de Celso Furtado para entender os problemas do subdesenvolvimento brasileiro, recorre-se a quatro obras do autor: Formação Econômica do Brasil (1958), Teoria e Política do Desenvolvimento Econômico (1967), Um Projeto para o Brasil (1968) e O Mito do Desenvolvimento Econômico (1974)5.

\footnotetext{
${ }^{5}$ A obra de Celso Furtado é vastíssima, entretanto, considerando as dimensões deste ensaio, entende-se que estas obras são representativas para o objetivo do trabalho. Os anos são referentes à primeira publicação da obra, e não coincidem, necessariamente,
} 
Sobre a formação econômica do Brasil, uma contribuição significativa de Celso Furtado é a chamada "teoria dos choques adversos". Para o autor, a industrialização brasileira foi uma resposta às dificuldades externas em decorrência da Primeira Guerra Mundial (1914-1918), da Grande Depressão (1929) e da Segunda Guerra Mundial (1939-1945). O ponto de inflexão, ou seja, a mudança do centro dinâmico teria ocorrido em 1930: até 1930 o crescimento industrial era induzido pelo crescimento resultante da expansão do setor exportador (café) e, a partir de 1930, a industrialização substitutiva de importações é estimulada pelo choque da crise do café e da Grande Depressão, bem como, pelas políticas econômicas adotadas para combater a crise.

\begin{abstract}
Ao manter-se a procura interna com maior firmeza que a externa, o setor que produzia para o mercado interno passa a oferecer melhores oportunidades de inversão que o setor externo. Cria-se, em consequência, um situação praticamente nova na economia brasileira, que era a preponderância do setor ligado ao mercado interno no processo de formação de capital (FURTADO, 2007, p. 277).
\end{abstract}

Assim, "o crescimento da procura de bens de capital, reflexo da expansão da produção para o mercado interno, e a forte elevação dos preços de importação desses bens, acarretada pela depreciação cambial, criaram condições propícias à instalação no país de uma indústria de bens de capital" (FURTADO, 2007, p. 279). Percebe-se que, para Furtado, a industrialização foi um subproduto das políticas de defesa do café, não havendo, por parte do Estado, uma intencionalidade para a industrialização do país nos anos 19306.

com os anos apresentados nas referências, uma vez que tive acesso à edições posteriores.

6 Entretanto, de acordo com Fonseca (2003), Furtado analisou políticas instrumentais (monetária, cambial e fiscal) e concluiu que a industrialização brasileira foi subproduto das políticas de defesa dos interesses do café. Porém, a política instrumental (monetária, cambial e fiscal) é um meio, e não um fim (educação, agricultura, indústria). Assim, num sentido amplo, as instituições (criação / alteração de códigos, órgãos, ministérios, regulamentação de relações de propriedade), ou seja, normas e comportamentos, revelam a consciência e a intencionalidade do governo para a industrialização. 
Mas qual foi o impacto dessa industrialização nascente para o desenvolvimento econômico do país? O desenvolvimento é um tema chave na obra de Celso Furtado.

A teoria do desenvolvimento trata de explicar, numa perspectiva macroeconômica, as causas e o mecanismo do aumento persistente da produtividade do fator trabalho e suas repercussões na organização da produção e na forma como se distribui e utiliza o produto social (FURTADO, 1971, p. 03).

Essa citação traz vários elementos centrais para compreender o que Celso Furtado entendia por desenvolvimento: a) não se trata de produtividade setorial, mas generalizada em toda economia; b) é macro no espaço (ocorre em vários lugares) e persistente no tempo; c) é um processo, dialeticamente o desenvolvimento é um vir a ser; d) o desenvolvimento significa as repercussões do crescimento, ou seja, a forma de distribuição e utilização do produto social. Esse ponto nos parece de suma importância, ainda mais considerando a época em que a obra foi escrita, pois era generalizada uma ideia de que desenvolvimento era igual a crescimento, e o que Celso Furtado nos demonstra é que não basta a economia crescer se não há distribuição dessa riqueza.

O desenvolvimento, para Celso Furtado, é um processo que precisa ser entendido numa dimensão histórica.

\begin{abstract}
O estudo (no tempo) das modificações das matrizes estruturais desses modelos que acompanham a intensificação da divisão social do trabalho, vale dizer: o aumento da produtividade do trabalho no plano macroeconômico e a diversificação da demanda no plano social - é a matéria central da teoria do desenvolvimento (FURTADO, 1983, p. 71-72).
\end{abstract}

Ao estudar o desenvolvimento, Celso Furtado, além das variáveis econômicas, introduz variáveis não econômicas (políticas, históricas e institucionais) na sua análise. Seu método é estruturalista, diferente, porém, do que se entende por estruturalismo na antropologia, por exemplo.

O que se entende por pensamento "estruturalista" em economia não tem relação direta com a escola estruturalista francesa, 
cuja orientação geral tem sido privilegiar o eixo das sincronias na análise social e estabelecer uma "sintaxe" das disparidades nas organizações sociais. O estruturalismo econômico (escola de pensamento surgida na primeira metade dos anos 50 entre economistas latino-americanos) teve como objetivo principal pôr em evidência a importância dos "parâmetros nãoeconômicos" dos modelos macroeconômicos. Como o comportamento das variáveis econômicas depende em grande medida desses parâmetros, e a natureza dos mesmos pode modificar-se significativamente em fases de rápida mudança social, ou quando se aplica o horizonte temporal na análise, os mesmos devem ser objeto de meticuloso estudo. Essa observação é particularmente pertinente com respeito a sistemas econômicos heterogêneos, social e tecnologicamente, como é o caso das economias subdesenvolvidas" (FURTADO, 1983, p. 72).

Para Celso Furtado, a estrutura do sistema econômico pode ser entendida como um conjunto de instituições, recursos naturais, dados técnicos e padrões de comportamento.

A estrutura do sistema econômico se funda nesses elementos institucionais, na base de recursos naturais, em dados técnicos e em certos padrões de comportamento que se definem em cada sociedade. É graças à relativa estabilidade desses elementos institucionais, físicos e psicológicos que as variáveis econômicas - entendidos como os principais elementos representativos da realidade econômica - representam uniformidades que podem ser objeto de análise (FURTADO, 1983, p. 82).

Qual é a "mola" do desenvolvimento? É a tecnologia. Entretanto, comparando a América Latina e a Europa, Celso Furtado aponta para uma diferença crucial: na Europa, especialmente no caso inglês, o aumento da tecnologia influenciava um aumento na produtividade, aumentando o excedente e o desenvolvimento da indústria. Com os salários crescentes, gerava um ciclo virtuoso para a acumulação de capital. Já na América Latina, a situação era diferente: com excesso de mão de obra e falta de capital, havia uma tendência a importar tecnologias de ponta, incompatíveis com relação ao mercado consumidor e ao emprego. Com a manutenção de baixos salários, o trabalhador não era incorporado como um consumidor, gerando o 
fenômeno conhecido como "subconsumismo" e a concentração de renda. "O subdesenvolvimento é, portanto, um processo histórico autônomo, e não uma etapa pela qual tenham, necessariamente, passado as economias que já alcançaram um grau superior de desenvolvimento" (FURTADO, 1983, p. 142)7.

Qual a proposta de Celso Furtado para romper com o subdesenvolvimento? No período de 1958/59 até 1967/68 (antes do "milagre"), o país entra numa fase de "estagnação" da economia.

Nosso ponto de partida é uma simples constatação: a economia brasileira, após dois decênios de rápido crescimento, ao impulso da industrialização substitutiva de importações, quando parecia haver reunido as condições para autogerar o seu desenvolvimento, foi afetada de uma paralisia que está transformando o atual decênio em uma das mais prolongadas crises de nossa história econômica moderna (FURTADO, 1968, p. 13).

Furtado se propõe a "identificar as causas dessa paralisia da economia brasileira" (p. 13) e conclui que "as causas últimas são complexas e estão enraizadas na estrutura do sistema econômico de nosso país" (p. 13). Pretendendo "passar diretamente da análise econômica a sugestões de ordem prática” (p. 14), Furtado afirma que é preciso uma "ação global, exercida sobre um conjunto de frentes articuladas" (p. 14) para "modificar de forma significativa a estrutura de um sistema econômico" (p. 14).

A hipótese base, ponto de origem das principais diretrizes esboçadas, é a seguinte: existe no sistema econômico deste país uma deformação estrutural que se traduz no perfil da demanda global. Essa deformação é responsável pela lenta penetração do progresso tecnológico em nossa economia e pela escassa difusão dos frutos dos aumentos de produtividade. (...) A ação sugerida é no sentido de modificação no perfil da demanda (FURTADO, 1968, p. 15).

\footnotetext{
7 Trata-se de uma crítica à Rostow (1974), para quem o desenvolvimento econômico das sociedades passava por etapas. "É possível enquadrar todas as sociedades, em suas dimensões econômicas, dentro de uma das cinco seguintes categorias: sociedade tradicional, as precondições para o arranco, o arranco, a marcha para a maturidade e a era do consumo em massa" (ROSTOW, 1974, p. 26).
} 
De modo geral, as sugestões para a modificação dessa deformação estrutural e desenvolver o país, estão baseadas na distribuição de renda, reforma agrária e investimento no fator humano, ou seja, pesquisa científica e tecnológica. "O desenvolvimento é a transformação do conjunto das estruturas de uma sociedade em função de objetivos que se propõe alcançar essa sociedade (FURTADO, 1983, p. 19-20). Portanto, o desenvolvimento precisa ser induzido, e o Estado, por meio do planejamento, possui papel central na determinação política do processo. Entretanto, a opção brasileira não foi por uma redistribuição de renda através da melhoria de salários, mas sim, de diminuição dos mesmos, aumentando a concentração de renda.

\begin{abstract}
Em síntese, a evolução estrutural do setor industrial, o progresso tecnológico e a tendência à concentração do poder econômico, atuaram de forma convergente no sentido de reduzir o fluxo de salários criado pelo setor industrial, relativamente ao valor da produção deste setor. Cabe inferir desta análise que o fruto do aumento substancial de produtividade ocorrido no setor industrial não foi transferido (ou o foi cada vez menos) para a massa da população assalariada (FURTADO, 1983, p. 35).
\end{abstract}

Essa já era a constatação antes do "milagre brasileiro" (19681973) e em 1974. No livro "O mito do desenvolvimento econômico", está a fase mais pessimista do autor ${ }^{8}$. Furtado analisa o problema do subdesenvolvimento e da dependência, destacando o caráter "estrutural" do subdesenvolvimento.

O subdesenvolvimento tem suas raízes numa conexão precisa, surgida em certas condições históricas, entre o processo interno de exploração e o processo externo de dependência. Quanto mais intenso o influxo de novos padrões de consumo,

8"O custo, em termos de depredação do mundo físico, desse estilo de vida, é de tal forma elevado que toda tentativa de generalizá-lo levaria inexoravelmente ao colapso de toda uma civilização, pondo em risco as possibilidades de sobrevivência da espécie humana. (...) a ideia de que os povos pobres podem algum dia desfrutar das formas de vida dos atuais povos ricos - é simplesmente irrealizável. Sabemos agora de forma irrefutável que as economias da periferia nunca serão desenvolvidas, no sentido de similares às economias que formam o atual centro do sistema capitalista. (...) Cabe, portanto, afirmar que a ideia de desenvolvimento econômico é um simples mito" (FURTADO, 1974, p. 75). 
mais concentrada terá que ser a renda. Portanto, se aumenta a dependência externa, também terá que aumentar a taxa interna de exploração. (...) Assim, taxas mais altas de crescimento, longe de reduzir o subdesenvolvimento, tendem a agravá-lo, no sentido de que tendem a aumentar as desigualdades sociais. Em conclusão: o subdesenvolvimento deve ser entendido como um processo, vale dizer, como um conjunto de forças de interação e capazes de reproduzir-se no tempo. Por seu intermédio, o capitalismo tem conseguido difundir-se em amplas áreas do mundo sem comprometer as estruturas sociais pré-existentes nessas áreas (FURTADO, 1974, p. 94).

E conclui que

a característica mais significativa do modelo brasileiro é a sua tendência estrutural para excluir a massa da população dos benefícios da acumulação e do progresso técnico. Assim, a durabilidade do sistema baseia-se grandemente na capacidade dos grupos dirigentes em suprimir todas as formas de oposição que seu caráter anti-social tende a estimular (FURTADO, 1974, p. 109).

Na obra "Desenvolvimento e Subdesenvolvimento" Furtado (2009) afirma que, no caso brasileiro, assim como nos demais países da América Latina, há um choque entre as modernas economias capitalistas, que estão em expansão, com estruturas arcaicas, gerando economias dualistas, híbridas, que combinam a assimilação do progresso técnico do capitalismo e estruturas pré-capitalistas, resultando no subdesenvolvimento. Assim, no Brasil o subdesenvolvimento seria uma forma complexa com três setores: subsistência, primário exportador e industrial. Portanto, o traço marcante das estruturas subdesenvolvidas são sistemas econômicos em que coexistem dois setores específicos, porém interdependentes: um atrasado e outro desenvolvido com amparo técnico (FURTADO, 2009).

De acordo com Arend (2008), na concepção de Celso Furtado, o subdesenvolvimento é um caso em que os aumentos de produtividade e assimilação de novas técnicas não conduziram à homogeneização social, mesmo causando uma elevação do nível de vida médio da população. A utilização do progresso técnico e do excedente econômico no subdesenvolvimento não foram obras do acaso, mas foram frutos de escolhas, sociais e políticas. "Para Furtado, o subdesenvolvimento é uma 
opção por uma forma de apropriação do excedente econômico que confere preponderância ao estilo de vida e ao consumo das elites" (AREND, 2008, p. 665). Portanto, "o processo de industrialização do Brasil não conduziu o país ao desenvolvimento" (AREND, 2008, p. 667).

Até aqui se apresentou a interpretação de Celso Furtado sobre os problemas estruturais do desenvolvimento brasileiro. Na sequência, analisa-se a interpretação de Raymundo Faoro, enfatizando as origens portuguesas do patrimonialismo e do estamento burocrático.

\section{O desenvolvimento do Brasil e a Herança Portuguesa em Raymundo Faoro: patrimonialismo e estamento burocrático}

Com o objetivo de entender como determinadas instituições impedem o desenvolvimento econômico brasileiro, vamos recorrer à obra "Os donos do poder" de Raymundo Faoro, escrita em 1958. Para compreender o Brasil, Faoro inicia sua investigação com a origem do Estado Português. A marca da interpretação de Faoro é o conceito de "estamento burocrático", uma instituição, que segundo o autor, foi herdada de Portugal e resiste ao tempo. Os conceitos de "Patrimonialismo (estado patrimonial)" e "capitalismo de Estado (capitalismo político)" complementam o conceito anterior ${ }^{9}$.

De Dom João I a Getúlio Vargas, numa viagem de seis séculos, uma estrutura político-social resistiu a todas as transformações fundamentais, aos desafios mais profundos, à travessia do oceano largo. O capitalismo politicamente orientado - o capitalismo político, ou o pré-capitalismo -, centro da aventura, da conquista e da colonização moldou a realidade estatal, sobrevivendo, e incorporando na sobrevivência o capitalismo moderno, de índole industrial, racional na técnica e fundado na liberdade do indivíduo - liberdade de negociar, de contratar, de gerir a propriedade sob a garantia das instituições. A comunidade política conduz, comanda, supervisiona os negócios, como negócios privados seus, na origem, como negócios públicos depois, em linhas que se demarcam gradualmente. O súdito, a sociedade, se compreende no âmbito

9 O conceito de estamento burocrático é inspirado em Weber. Para Weber (2005), existem três tipos de dominação: tradicional, carismático e racional-legal. A sociedade tradicional pode ser com, ou sem quadro burocrático. De acordo com Fonseca (2009), o patrimonialismo seria uma forma de dominação tradicional com quadro burocrático. 
de um aparelhamento a explorar, a manipular, a tosquiar nos casos extremos. Dessa realidade se projeta, em florescimento natural, a forma de poder, institucionalizada num tipo de domínio: o patrimonialismo, cuja legitimidade assenta no tradicionalismo - assim é porque assim sempre foi (FAORO, 2001, p. 819).

Para Faoro, o patrimonialismo é um modelo institucional que tem como forma de organização política gerida pela vontade administrativa do príncipe, o qual estava munido de todo um aparato de funcionários e de súditos leais que se apropriavam do Estado e que se utilizavam deste em benefício próprio, em caráter particularista.

Dominante o patrimonialismo, uma ordem burocrática, com o soberano sobreposto ao cidadão, na qualidade de chefe para funcionário, tomará relevo a expressão. Além disso, o capitalismo, dirigido pelo estado, impedindo a autonomia da empresa, ganhará substância, anulando a esfera das liberdades públicas, fundadas sobre as liberdades econômicas, de livre mercado, livre concorrência, livre profissão, opostas, aos monopólios e concessões reais (FAORO, 2007, p. 35).

O estamento é a camada que comanda a economia junto ao rei: "o Estado se aparelha, grau a grau, sempre que a necessidade sugere, com a organização político-administrativa, juridicamente pensada e escrita, racionalizada e sistematizada pelos juristas" (FAORO, 2007, p. 60).

Esta corporação de poder se estrutura numa comunidade: o estamento. Para a compreensão do fenômeno, observa-se, desde logo, que a ordem social, ao se afirmar nas classes, estamentos e castas, compreende uma distribuição de poder, em sentido amplo - a imposição de uma vontade sobre a conduta alheia (FAORO, 2007, p. 60).

O estamento, quadro administrativo e estado-maior de domínio, configura o governo de uma minoria. Poucos dirigem, controlam e infundem seus padrões de conduta a muitos. O grupo dirigente não exerce o poder em nome da maioria, mediante delegação ou inspirado pela confiança que do povo, como entidade global, se irradia. É a própria soberania que se enquista, impenetrável e superior, numa camada restrita, ignorante do dogma do predomínio da maioria (FAORO, 2007, p. 108). 
Assim, "o patrimonialismo, organização política básica, fecha-se sobre si próprio com o estamento, de caráter marcadamente burocrático. Burocracia não no sentido moderno, como aparelhamento racional, mas de apropriação do cargo" (FAORO, 2007, p. 102). Essa era a marca do estado português e que foi transposta para o Brasil, onde persistiu no tempo.

A realidade histórica brasileira demonstrou (...) a persistência secular da estrutura patrimonial, resistindo galhardamente, inviolavelmente, à repetição, em fase progressiva, da experiência capitalista. Adotou do capitalismo a técnica, as máquinas, as empresas, sem aceitar-lhe a alma ansiosa de transgredir (FAORO, 2007, p. 822).

No Brasil, "característico principal, o de maior relevância econômico e cultural, será o predomínio, junto ao foco superior de poder, do quadro administrativo, o estamento que, de aristocrático, se burocratiza (...) progressivamente, em mudança de acomodação e não estrutural" (FAORO, 2007, p. 823). De acordo com Faoro, no curso de nossa história, configurou-se um sistema de forças políticas que não muda.

Sobre a sociedade, acima das classes, o aparelhamento político - uma camada social, comunitária embora nem sempre articulada, amorfa muitas vezes - impera, rege, e governa, em nome próprio, num círculo impenetrável de comando. Esta camada muda e se renova, mas não representa a nação, senão que, forçada pela lei do tempo, substitui moços por velhos, aptos por inaptos, num processo que cunha e nobilita os recém-vindos, imprimindo-Ihes seus valores (FAORO, 2007, p. 824).

De acordo com Faoro (2007, p. 828), "a minoria governa sempre, em todos os sistemas políticos". O poder tem donos! O último parágrafo do livro faz uma belíssima síntese da obra, carregada de uma boa dose de pessimismo em relação às possibilidades de mudança frente à carga institucional mantida através dos tempos.

A cultura que poderia ser brasileira, frustra-se ao abraço sufocante da carapaça administrativa, trazida pelas caravelas de 
Tomé de Souza, reiterada na travessia de dom João VI, ainda regente de dona Maria I, a louca, dementada pelos espectros da Revolução Francesa. A terra virgem e misteriosa, povoada de homens sem lei nem rei, não conseguiu desarticular a armadura dos cavaleiros de El-Rei, herói burocrata. A máquina estatal resistiu a todas as setas, a todas as investidas da voluptuosidade das índias, ao contato de um desafio novo - manteve-se portuguesa, hipocritamente casta, duramente administrativa, aristocraticamente superior. Em lugar da renovação, o abraço lusitano produziu uma social enormity, segundo a qual velhos quadros e instituições anacrônicas frustram o florescimento do mundo virgem. Deitou-se remendo de pano novo em vestido velho, vinho novo em odres velhos, sem que o vestido se rompesse nem o odre rebentasse. $O$ fermento contido, a rasgadura evitada gerou uma civilização marcada pela veleidade, a fada que presidiu ao nascimento de certa personagem de Machado de Assis, claridade opaca, luz coada por um vidro fosco, figura vaga e transparente, trajada de névoa, toucada de reflexos, sem contornos, sombra que ambula entre as sombras, ser e não ser, ir e não ir, a indefinição das formas e da vontade criadora. Cobrindo-a, sobre o esqueleto de ar, a túnica rígida do passado inexaurível, pesado, sufocante (FAORO, 2007, p. 8378).

Faoro analisa o problema do subdesenvolvimento brasileiro com base em três conceitos: patrimonialismo, estamento burocrático e capitalismo político. Esses traços tiveram origem em Portugal, foram transpostos para o Brasil e permaneceram com o passar do tempo, sempre interferindo, negativamente, no desenvolvimento do país. O estamento burocrático (grupo que governa / manda / administra), ou seja, os donos do poder, fazem as leis e misturam tradição com privilégios legais. Apesar da mudança nos cargos políticos em função das eleições, a estrutura administrativa permanece e se adapta. Assim, o estamento burocrático passou pelo colonialismo, independência, república, processo de substituição de importações e governos militares. Portanto, a mudança é difícil, pois sempre existe um grupo que já sabe o que fazer e centraliza o poder político. No limite, "as coisas mudam para não mudar". Outras coisas simplesmente não mudam, como é o caso do estamento burocrático, que acaba virando uma instituição. 


\title{
Celso Furtado, Raymundo Faoro, Douglas North e as similaridades conceituais sobre as características do (não) desenvolvimento brasileiro
}

Arend (2008), fazendo uma comparação entre Celso Furtado e Raymundo Faoro, destaca que os dois autores buscaram explicar quais as causas do atraso econômico brasileiro, entendido como o "nãodesenvolvimento".

\begin{abstract}
O principal ponto de encontro entre os dois autores para a resposta desta pergunta certamente reside no fato de que, ao longo dos tempos, no Brasil, o capitalismo adquiriu um caráter elitista e não-democrático, provocador de heterogeneidade social. Os dois autores, para explicarem esse fenômeno valemse do conceito de modernização. A modernização, de que falam os dois autores, acarreta um processo de ruptura com a cultura local, que impede com que aflore o capitalismo industrial e, conseqüentemente, o desenvolvimento econômico autônomo (AREND, 2008, p. 667-8). Grifos do autor.
\end{abstract}

Assim, à luz da Nova Economia Institucional, poder-se-ia perguntar: o que esses três autores (Douglas North, Celso Furtado e Raymundo Faoro) possuem em comum: Entre outras questões, podemse destacar três aspectos importantes: instituições, história e elites.

O primeiro aspecto refere-se ao papel das instituições no desenvolvimento econômico. De acordo com North (1994b, p. 07), "o desempenho econômico é função das instituições e de sua evolução". De modo geral, o que Celso Furtado chamou de parâmetros não econômicos (políticos, históricos e institucionais) da estrutura do sistema econômico e Raymundo Faoro de patrimonialismo e estamento burocrático podem ser lidos como instituições.

O segundo elemento pode ser resumido na seguinte expressão: a história importa! Douglass North chamou de path dependence, ou seja, a dependência da trajetória histórica. Conforme destacamos no início deste ensaio, há uma unanimidade entre os intérpretes do Brasil: nosso "atraso" não é uma questão genética, climática ou geográfica, mas sim, uma questão histórica.

A terceira questão refere-se ao papel das elites. De acordo com North (1994b, p. 27-8), "as organizações políticas e econômicas de uma nação e seus empresários tomam as decisões que determinam o 
desempenho econômico, sendo limitadas pelo arcabouço institucional vigente e pelos construtos mentais". Para Furtado (1974, p. 109), "a característica mais significativa do modelo brasileiro é a sua tendência estrutural para excluir a massa da população dos benefícios da acumulação e do progresso técnico". De acordo com Faoro, "impostas por elites pseudodissidentes, em favor dos seus próprios interesses, essas modernizações mantém a maioria da população alijada de benefícios sociais elementares" (FAORO, 1992, p. 22).

Portanto, Celso Furtado e Raymundo Faoro, recorrendo à história e às instituições para explicar o "atraso" brasileiro, evidenciam dois problemas graves que persistem no Brasil, ou seja, as desigualdades sociais e a pobreza. Corroborando com esta constatação, um argumento relevante é apresentado pelo sociólogo brasileiro José de Souza Martins no sugestivo livro "a sociedade vista do abismo": Para o esse autor, "o desenvolvimento econômico que gera um desenvolvimento social muito aquém de suas possibilidades, como ocorre nos países do Terceiro Mundo e como ocorre no Brasil, nega-se na perversidade das exclusões sociais que dissemina". (Martins, 2008, p. 09).E mais adiante complementa:

Em suas consequências sociais adversas, o modelo de desenvolvimento econômico que se firmou no mundo contemporâneo leva simultaneamente a extremos de progresso tecnológico e de bem-estar para setores limitados da sociedade e a extremos de privação, pobreza e marginalização social para outros setores da população. Na medida em que hoje o objetivo do desenvolvimento econômico é a própria economia, podemos defini-lo como um modelo antidesenvolvimento: o desenvolvimento econômico é descaracterizado e bloqueado nos problemas sociais graves que gera, mais do que legitimado nos benefícios socialmente exíguos que cria e distribui (MARTINS, 2008, p. 13).

O processo de elaboração desse ensaio e a reflexão sobre os problemas de desenvolvimento do Brasil remeteram a um livro de José de Souza Martins, que trata do poder da tradição que dificulta mudanças. Trata-se da obra "o poder do atraso". De acordo com Martins (1994), não é possível entender o Brasil sem levar em consideração uma contradição, ou seja, a combinação do moderno e do tradicional que freia o desenvolvimento social e político do Brasil e que se renova a 
cada momento. Para o autor, o Brasil é vítima de um atraso político e econômico!

(...) na sociedade brasileira, a modernização se dá no marco da tradição, o progresso ocorre no marco da ordem. Portanto, as transformações sociais e políticas são lentas, não se baseiam em acentuadas e súbitas rupturas sociais, culturais $e$ institucionais. O novo surge sempre como um desdobramento do velho (Martins, 1994, p. 30). Grifos no original.

Em 2011, o autor (re)editou "O poder do atraso" com alguns acréscimos sob o título de "A política do Brasil lúmpen e místico" (MARTINS, 2011). Entretanto, quase duas décadas depois, e com as experiências de dois governos "diferentes", as conclusões são praticamente as mesmas. Para José de Souza Martins, o Brasil apresenta uma "estranha peculiaridade histórica que é de avançar economicamente, atenuar socialmente e recuar politicamente" (MARTINS, 2011 , p. 13).

Portanto, as constatações atuais desse renomado sociólogo demonstram que o debate sobre o atraso brasileiro ainda não foi vencido, tanto no campo político-econômico quanto acadêmico. Por outro lado, apesar de José de Souza Martins não citar Douglass North, também está referindo-se às instituições e aos processos de mudança, ou (não) mudança institucional, revelando o peso da história e da tradição nos processos de desenvolvimento do Brasil. 


\section{CONSIDERAÇÕES FINAIS}

A reflexão sobre as características do desenvolvimento brasileiro, sobretudo ao abordar os seus principais entraves, é discussão não vencida, tanto no âmbito político-econômico como nos debates acadêmicos. Por esse motivo, a contribuição original de José de Souza Martins (1994 e 2011) foi retomada ao finalizar a seção anterior. Esse autor reforça o peso da tradição como uma das peculiaridades do país, denotando avanços econômicos, certa anestesia social e retrocessos políticos.

Portanto, para tentar compreender essas características do processo de desenvolvimento do Brasil, o objetivo deste ensaio foi buscar nas obras clássicas de Celso Furtado e Raymundo Faoro, ambos intérpretes do Brasil da geração dos anos 1950, elementos teóricos para tentar explicar o atraso brasileiro. A leitura dos clássicos foi feita com base nas contribuições do economista Douglass North, enfatizando os elementos institucionais deste processo. As instituições são entendidas como o conjunto de regras formais e informais, bem como as características da sua aplicação.

Douglass North demonstra que o processo de desenvolvimento (crescimento, estagnação ou pobreza) é resultado das instituições e da sua evolução histórica, havendo grande dependência de determinadas trajetórias escolhidas. Por exemplo, no caso do desenvolvimento rural brasileiro, nos anos 1960, houve a opção por uma modernização conservadora, que alterou a base tecnológica, sem modificar a estrutura fundiária, com uma ampla reforma agrária. Assim, a trajetória do desenvolvimento rural brasileiro é dependente desta decisão institucional.

Celso Furtado e Raymundo Faoro, apesar de não utilizarem o conceito de instituições da maneira como Douglass North, referem-se a processos semelhantes, ou seja, o que Celso Furtado chamou de parâmetros não econômicos (políticos, históricos e institucionais) da estrutura do sistema econômico e Raymundo Faoro, de patrimonialismo e estamento burocrático.

De modo geral, os três autores ao interpretar o processo de desenvolvimento, enfatizam a importância das instituições, da história e o papel das elites. Já os argumentos de José de Souza Martins 
demonstram a atualidade desse debate dos anos 1950, uma vez que o atraso brasileiro ainda não se encerrou, ou seja, continua uma sociedade de história lenda, avança, sem avançar.

\section{REFERÊNCIAS}

AREND, Marcelo. Atraso via modernização cultural: uma leitura evolucionista das obras de Raymundo Faoro e Celso Furtado. Economia. v. 9, n.3, set/dez, 2008. pp. 651-681.

FAORO, Raymundo. Os donos do poder. formação do patronato político brasileiro. 3. ed. rev. São Paulo: Globo, 2001.

A questão nacional: a modernização. Estudos Avançados. v.6 n.14 Jan./Apr., 1992.pp. 07-22.

FIANI, Ronaldo. Estado e economia no institucionalismo de Douglass North. Revista de Economia Política. v. 23, n. 2 (90), abril / junho, 2003. pp. 135-49.

FONSECA, Pedro Cezar Dutra. Sobre a intencionalidade da política industrializante do Brasil na década de 30. Revista de Economia Política. v. 23, n. 1 (89), janeiro-março, 2003. pp. 133-148.

FURTADO, Celso. Desenvolvimento e subdesenvolvimento. 5. ed. Rio de Janeiro: Contraponto/Centro Internacional Celso Furtado, 2009.

. Formação econômica do Brasil.34. ed.São Paulo: Companhia das Letras, 2007.

Teoria e política do desenvolvimento econômico. São Paulo:Abril Cultural, 1983.

Teoria e política do desenvo/vimento econômico. São Paulo:

Companhia Editora Nacional, 1971.

Um projeto para o Brasil. 4. ed. Rio de Janeiro: Saga, 1968. 
O mito do desenvolvimento econômico. Rio de Janeiro: Paz e Terra, 1974.

GIAMBIAGI, Fabio et . Economia brasileira contemporânea. Rio de Janeiro: Elsevier, 2005.

HOBSBAWM, Eric. Era dos extremos: o breve século xx: 1914-1991. São Paulo: Companhia das Letras, 1995.

MARTINS, José de Souza. $O$ poder do atraso: ensaios de sociologia e história lenta. São Paulo: Hucitec, 1994.

A sociedade vista do abismo: novos estudos sobre exclusão, pobreza e classes sociais. 3. ed. Petrópolis: Vozes, 2008.

A política do Brasil lúmpen e místico. São Paulo: Contexto, 2011.

NORTH, Douglass C. Institutions, institutional change and economic performance. Cambridge: Cambridge University Press, 1990.

Economic performance through time. The American Economic Review. v. 84, n. 3, jun, 1994a. pp. 359-68.

Custos de transação, instituições e desempenho econômico. Rio de Janeiro: Instituto Liberal, 1994b.

. Entrevista: Douglass North. Revista Veja. Edição 1830. 26 de novembro de 2003.

-----.. Desempeño económico enel transcurso de losaños. Conferência de Douglass C. North em Estocolmo, Suécia, 9 de dezembro de 1993 ao receber o Prêmio Nobel de Ciências Econômicas. Disponível em: $<$ http://www.eumed.net/cursecon/textos/north-nobel.htm>. Acesso em 15 set. 2009. 
PNUD, Programa das Nações Unidas para o Desenvolvimento. Atlas do desenvolvimento humano. Disponível em $<$ www.pnud.org.br $>$. Acesso em 12 jan. 2010.

ROSTOW, W. W. Etapas do desenvolvimento econômico: um manifesto não-comunista. 5. ed. Rio de Janeiro: Zahar, 1974.

SIMAN, Renildes Fortunato; CONCEIÇÃO, Octavio A. C.; FILIPPI, Eduardo Ernesto. A economia institucional: em busca de uma teoria do desenvolvimento rural. Perspectiva Econômica. v. 2, n. 2. jul/dez, 2006. pp. 37-55.

WEBER, Max. Max Weber. Coleção Grandes Cientistas Sociais. Coordenação de Florestam Fernandes. 7. ed. São Paulo: Ática, 2005.

Submetido em 24/06/2015.

Aprovado em 15/10/2015.

Sobre o autor

\section{Clério Plein}

Doutor e Mestre em Desenvolvimento Rural (PGDR/UFRGS), bacharel em Economia Doméstica pela Universidade Estadual do Oeste do Paraná - UNIOESTE, professor e pesquisador da UNIOESTE.

Endereço: Rua Maringá, 1200, bairro Vila Nova. 85605010 - Francisco Beltrão, PR Brasil.

E-mail: clerioplein@ig.com.br. 